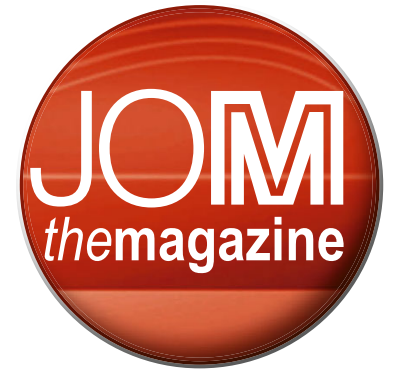

\section{TMS Board of Directors}

David H. DeYoung

President

Director, Research and Development, Alcoa

\section{Stanley M. Howard}

Past President

Professor Emeritus,

South Dakota School of

Mines \& Technology

Kevin J. Hemker

Vice President

Alonzo G. Decker Chair in

Mechanical Engineering,

Johns Hopkins University

Joy H. Forsmark

Financial Planning Officer

Technical Expert,

Light Cast Metals,

Ford Motor Company

Amy J. Clarke

Director, Membership \&

Student Development

Scientist, Los Alamos

National Laboratory

Michele V. Manuel

Director, Content

Development \&

Dissemination

Professor,

University of Florida

\section{Alan A. Luo \\ Director/Chair \\ Light Metals Division \\ Professor and Director, \\ Light Metals and \\ Manufacturing \\ Research Laboratory, \\ The Ohio State University}

\title{
2017TMS President David DeYoung: Building on What Makes TMS Special
}

\author{
David H. DeYoung
}

\section{TMS board motions, minutes, and musings}

This regular JOM feature offers news and perspectives on TMS governance, as well as Board of Directors activities, priorities, and decisions. To find out how you can become involved in these initiatives, contact James J. Robinson, TMS Executive Director, at robinson@ @tms.org.

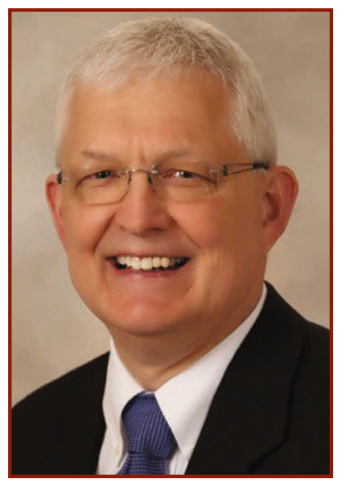

David H. DeYoung
As I walked up to the lectern at the Carl Wagner Symposium at the TMS 1981 Annual Meeting, I recognized in the audience some of the legends of chemical metallurgy. I'm sure each of you can

imagine the effect that this realization had on my already unsettled nerves, as a Ph.D. student and first-time presenter. At the conclusion of my talk, the audience threw out tough questions, and then a lively debate on slag chemistry and structure ensued among the audience. Walking back to my seat, I was convinced that my talk didn't go well at all. So, the positive feedback I later received from John Elliott, my thesis advisor, took me by surprise. Whenever you get the audience involved, he explained, you've done a good job. Reflecting now on that first TMS experience leaves me with a thought: Where besides TMS could one engage with the best in the world?

TMS is special because of the relationships it fosters among its members-be they nervous young graduate students interacting with legends of the field, new professionals being taken under wing by the well-established, or even veteran researchers energized by fresh or unconventional approaches of young minds. Every invention, every development, every new insight builds on the work of others. We make progress as a team, and strong teams have strong relationships at their foundations. These may be personal connections made at conferences, collaborative connections made while serving on technical committees, or even indirect connections made while reading the work of others in technical journals. TMS forges all of these.
I have always enjoyed building things when I wasn't studying or working. As a teenager growing up just outside of Chicago, I had access to wonderful museums only a 45-minute train ride away. In an optical shop at the Adler Planetarium, I learned to make a telescope, grinding and polishing the six-inch reflector by hand. My friends had a strong interest in astronomy, and I did also at the time, but I later realized that my greatest satisfaction came from building the telescope.

But there can be no building without building blocks. Materials are the building blocks of society's progress. Materials are so important that they are even embedded in our social vocabulary: the Bronze Age, the Athenian Golden Age, Silicon Valley. Even Superman's nickname is "Man of Steel." TMS is special because its members, as materials professionals, discover and create the building blocks of the future. We are privileged to be involved in virtually all technological developments: from computer chips to airplanes, from smartphones to rockets. Our members invent materials with unique functions and properties, and develop processes to produce materials in more affordable and sustainable ways. 
After my freshman year in college, I landed a summer job as a laborer in an iron foundry, which ultimately led me to choose metallurgy as my profession. In that foundry, the castings were the beginnings of products that one could encounter in the "real world." Pipe wrench handles and differential housings are two of the products that I recall. However, it was the processing steps that really piqued my curiosity. Sure, everyone understands that in a foundry, molten metal is poured into molds to make objects of particular shapes. But, why were some parts packed into metal baskets, sprinkled with charcoal, and then sent into a long tunnel furnace? I wanted to understand why.

TMS is special because, as materials professionals, we all want to understand why. We make the "why" an integral part of what we do at TMS, covering the landscape from the highly theoretical to the highly practical. We make the connections from atoms and molecules to bridges and airplanes. The strong participation we have from academia, industry, and government labs - one of the defining features of our societyis a testament to our focus on these connections.
As TMS President, I look forward to building and strengthening these and other features that make TMS special. Our strategic roadmap is a set of initiatives that has been carefully developed by our Board of Directors and set in motion.

First, TMS is an international society. More than one-half of our attendees to the annual meeting come from locations outside the United States. We benefit greatly from this diversity. We need to continue to foster international participation in the membership and leadership of the society.

Second, TMS has made progress in diversity and inclusion. We were the first materials society to organize a diversity conference, and our third such conference is in the planning stages. We need to continue these efforts. It is the right thing to do, and diversity and inclusion leads to diversity in thought which leads to solutions and progress for society.

Third, our industrial participation needs to be reinforced, and as someone who has spent a career in industry, this is a topic near and dear to me. TMS has so much to offer as an intersection between industry, academia, and government. TMS provides a forum in which we can coordinate our efforts across sectors and ensure that the fruits of our combined labor most effectively benefit society.

Finally, we need to continue to advance material solutions for megatrends in the world, such as new energy and environmental challenges. I believe we need to find ways to use our diverse member base to more quickly identify major challenges and address them. Our technical divisions and committees are a great resource that could be leveraged in a strategic way. To remain relevant, the speed of change in TMS needs to match the speed of change in today's world.

I ask all of you, as members, to review these strategic initiatives and volunteer to help move them forward. As we together look to TMS's future, Benjamin Franklin's advice remains relevant: "Tell me and I forget. Teach me and I remember. Involve me and I learn."

\section{TMS Endorses Statement on U.S. Immigration and Visa System}

TMS has joined 14 other engineering societies in issuing a statement to the U.S. president and congress "to work with all interested parties to ensure that our country's visa and immigration systems maintain the flow of individuals and ideas upon which our country's prosperity and progress depend." The other signatories on the statement are AAES, ABET, AIAA, AIChE, ANS, ASABE, ASCE, ASEE, ASME, HFES, IEEE-USA, OSA, SAE, and SPIE.

The statement was delivered in February 2017 and is posted in the Public \& Government Affairs section of www.tms.org. 